\title{
ACE2 Polymorphisms Reflected on the Immune and Apelinergic Peptide Systems: Potential COVID-19 Tools for Risk Stratification and Therapy.
}

\author{
Mina Kelleni ${ }^{1}$ \\ ${ }^{1}$ Affiliation not available
}

July 1, 2021

\begin{abstract}
ACE2 polymorphisms have been previously linked to increased susceptibility to multiple diseases and are currently linked to SARS CoV-2 susceptibility and complications. Notably, ACE2 transcribed or regulated proteins include the activity of metaloproteinsase-2 and apelin-13 and 36, might be linked to abnormal immune responses and complications. Potential genetic or serological tests might be developed to detect the higher vulnerable groups to SARS CoV-2 complications and/or mortality. Moreover, we postulate that diabetic and obese patients suffer from exhausted and/or abnormally functioning apelinergic peptides that predispose them to a higher severe COVID-19 risk. Finally, infusion of apelin-13 to treat selected critical cases of COVID-19, especially those complaining of refractory advanced heart failure, might be considered for clinical trials.
\end{abstract}

\section{Hosted file}

SARS CoV-2 apelinergic link updated1.pdf available at https://authorea.com/users/318758/ articles/522100-ace2-polymorphisms-reflected-on-the-immune-and-apelinergic-peptidesystems-potential-covid-19-tools-for-risk-stratification-and-therapy

\section{Hosted file}

SARS CoV-2 apelinergic link updated.pdf available at https://authorea.com/users/318758/ articles/522100-ace2-polymorphisms-reflected-on-the-immune-and-apelinergic-peptidesystems-potential-covid-19-tools-for-risk-stratification-and-therapy 